\title{
Transformation-specific matrix metalloproteinases, MMP-7 and MMP-13, are present in epithelial cells of keratoacanthomas
}

\author{
Tiina T Kuivanen ${ }^{1}$, Leila Jeskanen ${ }^{2}$, Lauri Kyllönen ${ }^{3}$, Ulla Impola ${ }^{1}$ and \\ Ulpu K Saarialho-Kere ${ }^{1,4}$
}

\begin{abstract}
${ }^{1}$ Department of Dermatology, Helsinki University Central Hospital and Biomedicum Helsinki, Helsinki, Finland; ${ }^{2}$ Department of Pathology, Helsinki University Central Hospital and Biomedicum Helsinki, Helsinki, Finland; ${ }^{3}$ Department of Transplantation Surgery, Helsinki University Central Hospital and Biomedicum Helsinki, Helsinki, Finland and ${ }^{4}$ Department of Dermatology, Karolinska Institutet at Stockholm Söder Hospital, Stockholm, Sweden
\end{abstract}

\begin{abstract}
Keratoacanthomas are rapidly growing hyperproliferative skin tumors that may clinically or histologically be difficult to distinguish from well-differentiated squamous cell cancers (SCCs). UV light, trauma, and immune suppression represent their etiological factors. As matrix metalloproteinases (MMPs) are implicated at all stages of tumorigenesis, we investigated the expression profile of several cancer-related MMPs to find markers that would differentiate keratoacanthomas from SCCs and shed light to the pathobiology of keratoacanthoma. Samples from 31 keratoacanthomas and 15 grade I SCCs were studied using immunohistochemistry for MMP-2, $-7,-8,-9,-10,-13$, and -19 and 16 and laminin-5 2 chain. In situ hybridization for MMP-7, -10, and -13 was performed in a subset of tumors. Keratinocytes with atypia, presence of neovascularization, and composition of the inflammatory infiltrate were graded from hematoxylin-eosin stainings. MMP-7 was present in the epithelium of 4/31 keratoacanthomas and 9/15 SCCs, MMP-8 in 3/30 keratoacanthomas and 0/15 SCCs, but MMP-13 in 16/31 keratoacanthomas and 10/15 SCCs, and MMP-10 in 28/31 keratoacanthomas and all cancers. MMP-9 was detected in the epithelium in 5/31 keratoacanthomas and 8/15 SCCs, whereas MMP-2 was only present in fibroblasts in both tumors. MMP-19 was upregulated in proliferating epithelium of keratoacanthomas as was p16. Cytoplasmic laminin-5 22 was particularly abundant in keratinocytes at the pushing border of MMP-13positive keratoacanthomas. We conclude that although some MMPs (MMP-10 and -13) are abundantly expressed in keratoacanthomas, the presence of MMP-7 and -9 in their epithelial pushing border is rare and should raise suspicion of SCC. Further, the loss of MMP-19 and p16 could aid in making the differential diagnosis between well-differentiated SCC and keratoacanthoma. Frequent expression of the transformationspecific MMP-13 in keratoacanthomas suggests that they are not benign tumors but incomplete SCCs. Modern Pathology (2006) 19, 1203-1212. doi:10.1038/modpathol.3800633; published online 12 May 2006
\end{abstract}

Keywords: MMP-8; MMP-9; MMP-10; squamous cell cancer; laminin-5; immune suppression

Keratoacanthomas are squamous neoplasms most likely derived from hair follicle cells on sunexposed skin. ${ }^{1}$ They present clinically with a rapid growth phase for the first 4-8 weeks and a possible spontaneous self-induced regression after 3-6 months. ${ }^{2}$ The origin of keratoacanthomas is uncertain. UV light may be of etiologic significance as

Correspondence: Professor UK Saarialho-Kere, MD, PhD, Department of Dermatology, Helsinki University Central Hospital and Biomedicum Helsinki, Meilahdentie 2, Helsinki 00250, Finland. E-mail: ulpu.saarialho-kere@helsinki.fi

Received 21 December 2005; revised and accepted 24 April 2006; published online 12 May 2006 well as some chemical agents, immune suppression, and trauma. ${ }^{1,3}$

Differential diagnosis between keratoacanthomas and well-differentiated squamous cell cancers (SCCs), based on clinical and histomorphological data, may be problematic and there are some reports on lesions classified as keratoacanthoma that have metastasized. ${ }^{4}$ It is thought that those keratoacanthomas of sun-exposed locations and diagnosed in older patients may more frequently progress to SCC. ${ }^{5}$ Some authors believe that keratoacanthoma is a well-differentiated variant of SCC representing a range of neoplastic activity with no clear distinction, whereas some authors consider the histological and cytological differentiation precise, sure, and 
possible. ${ }^{1,5-7}$ Thus, the natural behavior of keratoacanthomas remains unclear and controversial, and practically all these tumors are currently surgically excised. $^{3}$ In addition to the proportion of cells with atypia, one malignancy-associated criterion in keratoacanthomas is increased microvessel density. ${ }^{5}$

Matrix metalloproteinases (MMPs), a family of 23 human zinc-dependent proteolytic enzymes, have been implicated at all stages of tumorigenesis. ${ }^{8}$ They mediate apoptosis, proliferation, and differentiation, tumor angiogenesis, and malignant conversion ${ }^{9}$ by degrading basement membranes and various matrix components as well as by activating chemokines and growth factors. Particularly MMP-1, -2, -7, -9, $-13,-14$, and -26 have been shown to be present in well-differentiated cutaneous SCC. ${ }^{10-12}$ Paradoxically, recent data show that some novel MMPs are in fact instrumental for normal keratinocyte proliferation (MMP-19 and -28) and disappear in cancer, ${ }^{13,14}$ whereas MMP-3, -7, -9, and -12 effectively cleave plasminogen to angiostatin and type XVIII collagen to endostatin, leading to inhibition of angiogenesis and eventually retardation of tumor growth. ${ }^{15,16}$ Our recent results suggest that epithelial expression of MMP-7, -12 , and -13 , but not that of MMP-1, -3, -8, -9, and -10, in chronic wounds provides a diagnostic clue for distinguishing welldifferentiated SCCs from nonmalignant wounds. ${ }^{17}$

It is of major interest to find markers that distinguish keratoacanthoma from SCC and to better define the pathobiologic steps in its development. The aim of this study was to investigate whether the pattern of epithelial MMP expression can differentiate keratoacanthomas from SCCs. Furthermore, we also stained for two other cancer-related molecules, laminin-5 $\gamma 2$ and p16. Laminin-5 $\gamma 2$ serves as migrating substrate in neoplasia and stimulates invasion after having been cleaved by, for example, MMP$2,{ }^{18,19}$ whereas mutational loss of p16 is a frequent early event in the development of SCC. ${ }^{20}$

\section{Materials and methods}

\section{Patients and Tissues}

Formalin-fixed, paraffin-embedded samples from 31 patients with keratoacanthoma (Table 1) and 15 patients with grade I SCC (Table 2) were obtained from the Departments of Dermatopathology and Pathology, University of Helsinki, Finland. Three of our patients were immunosuppressed following organ transplantation. Diagnoses were made by an

Table 1 Epithelial expression pattern of MMPs and other proteins in KAs

\begin{tabular}{|c|c|c|c|c|c|c|c|c|c|c|c|c|c|}
\hline Patient & Age/sex & Area & Infl. & Atypia & Angiog. & $M M P-7$ & $M M P-8$ & $M M P-9$ & $M M P-10$ & $M M P-13$ & $M M P-19$ & LN5 & P16 \\
\hline $1^{\mathrm{a}}$ & $83 / \mathrm{M}$ & Neck & 5 & 2 & 1 & - & $t^{\mathrm{b}}$ & + & +++ & ++ & + & 3 & 1 \\
\hline $2^{\mathrm{a}}$ & $81 / F$ & Arm & 4 & 0 & 2 & - & - & - & + & ++ & + & 1 & 2 \\
\hline $3^{a}$ & $46 / \mathrm{M}$ & Nose & 2 & 1 & 1 & - & $-^{\mathrm{b}}$ & - & + & ++ & + & 2 & 2 \\
\hline $4^{a}$ & $73 / \mathrm{M}$ & Temple & 3 & 2 & 1 & + & $-^{\mathrm{b}}$ & - & + & ++ & + & 2 & 0 \\
\hline $5^{\mathrm{c}}$ & $89 / F$ & Leg & 6 & 0 & 3 & - & $-^{\mathrm{b}}$ & - & - & ++ & + & 1 & 1 \\
\hline $6^{\mathrm{c}}$ & $55 / F$ & Lip & 6 & 0 & 3 & ++ & $-^{\mathrm{b}}$ & - & - & ++ & + & 2 & 1 \\
\hline $7^{\mathrm{a}}$ & $76 / F$ & Cheek & 4 & 0 & 2 & - & $-^{\mathrm{b}}$ & + & ++ & + & ++ & 2 & 2 \\
\hline $8^{a}$ & $75 / \mathrm{M}$ & Cheek & 6 & 0 & 1 & - & $-^{\mathrm{b}}$ & - & + & + & ++ & 1 & 2 \\
\hline $9^{\mathrm{a}}$ & $54 / F$ & Arm & 2 & 0 & 0 & - & - & - & + & + & + & 1 & 2 \\
\hline $10^{\mathrm{a}}$ & $81 / \mathrm{M}$ & Cheek & 4 & 0 & 1 & - & + & - & ++ & + & + & 2 & 0 \\
\hline $11^{\mathrm{a}}$ & $57 / F$ & Cheek & 4 & 0 & 1 & - & $-^{\mathrm{b}}$ & - & + & + & + & 2 & 1 \\
\hline $12^{\mathrm{a}}$ & $50 / \mathrm{M}$ & Lip & 3 & 0 & 1 & - & $-^{\mathrm{b}}$ & + & ++ & + & - & 1 & 1 \\
\hline $13^{\mathrm{a}}$ & $69 / \mathrm{F}$ & Leg & 2 & 0 & 1 & - & - & - & + & + & + & 2 & 2 \\
\hline $14^{\mathrm{c}}$ & $63 / \mathrm{F}$ & Nose & 3 & 1 & 1 & - & - & - & + & + & + & 1 & 3 \\
\hline $15^{\mathrm{a}}$ & $86 / F$ & Forehead & 2 & 0 & 1 & - & ${ }^{\mathrm{b}}$ & + & + & + & - & 1 & 1 \\
\hline $16^{\mathrm{a}}$ & $56 / F$ & Eyelid & 2 & 0 & 0 & - & - & - & - & + & + & 2 & 1 \\
\hline $17^{\mathrm{c}}$ & $62 / \mathrm{M}$ & Abdomen & 2 & 1 & 1 & - & + & - & + & - & + & 2 & 3 \\
\hline $18^{\mathrm{a}}$ & $53 / \mathrm{F}$ & Arm & 2 & 0 & 0 & - & ND & - & ++ & - & + & 1 & 2 \\
\hline $19^{\mathrm{a}}$ & $74 / F$ & Abdomen & 2 & 0 & 0 & - & - & - & + & - & + & 1 & 2 \\
\hline $20^{\mathrm{c}}$ & $60 / \mathrm{F}$ & Nose & 4 & 1 & 1 & - & $-^{\mathrm{b}}$ & - & + & - & - & 2 & 2 \\
\hline $21^{\mathrm{c}}$ & $89 / F$ & Cheek & 5 & 1 & 1 & - & - & - & +++ & - & + & 1 & 0 \\
\hline $22^{\mathrm{c}}$ & $72 / \mathrm{M}$ & Lip & 2 & 0 & 2 & - & - & - & + & - & + & 1 & 3 \\
\hline $23^{\mathrm{c}}$ & $61 / \mathrm{M}$ & Chest & 4 & 1 & 1 & - & $-{ }^{\mathrm{b}}$ & + & +++ & - & - & 2 & 2 \\
\hline $24^{\mathrm{a}}$ & $79 / \mathrm{M}$ & Back & 4 & 0 & 0 & - & $-^{\mathrm{b}}$ & - & + & - & + & 2 & 2 \\
\hline $25^{\mathrm{a}}$ & $73 / \mathrm{F}$ & Forehead & 5 & 0 & 1 & + & - & - & + & - & + & 1 & 2 \\
\hline $26^{\mathrm{a}}$ & $85 / F$ & Temple & 2 & 0 & 0 & ND & - & - & + & - & + & 1 & 2 \\
\hline $27^{\mathrm{a}}$ & $55 / F$ & Arm & 3 & 0 & 0 & - & - & - & + & - & + & 2 & 3 \\
\hline $28^{\mathrm{c}}$ & $74 / \mathrm{F}$ & Temple & 6 & 0 & 1 & + & - & - & + & - & + & 1 & 1 \\
\hline $29^{c}$ & $58 / \mathrm{F}$ & Temple & 6 & 0 & 3 & - & - & - & + & - & + & 0 & 0 \\
\hline $30^{\mathrm{a}}$ & $79 / \mathrm{M}$ & Forehead & 3 & 0 & 1 & - & $-^{\mathrm{b}}$ & - & ++ & - & + & 0 & 2 \\
\hline $31^{\mathrm{a}}$ & $74 / F$ & Cheek & 3 & 0 & 0 & - & - & - & + & - & + & 2 & 1 \\
\hline
\end{tabular}

${ }^{\mathrm{a}}$ Classical KA with symmetrical structure and sharply demarcated pushing border.

${ }^{\mathrm{b}}$ Positive neutrophils, $\mathrm{ND}=$ not determined.

${ }^{\mathrm{C}}$ Unclassical KA with asymmetrical structure and unevenly demarcated pushing border. Infl. =inflammation; Angiog. =angiogenesis; LN5 = laminin-5 $\gamma 2 ; \mathrm{KA}=$ keratoacanthomas; $\mathrm{MMP}=$ matrix metalloproteinase. 
Table 2 Epitelial expression of MMPs in KAs and well-differentiated cutaneous SCCs

\begin{tabular}{lccccccc}
\hline & $M M P-2$ & $M M P-7$ & $M M P-8$ & $M M P-9$ & $M M P-10$ & $M M P-13$ & $M M P-19$ \\
\hline KA & $0 / 31$ & $4 / 31$ & $3 / 30$ & $5 / 31$ & $28 / 31$ & $16 / 31$ & $27 / 31$ \\
SCC & $0 / 15$ & $9 / 15^{*}$ & $0 / 15$ & $8 / 15^{*}$ & $15 / 15$ & $11 / 15$ & $6 / 15^{* *}$ \\
\hline
\end{tabular}

${ }^{*} P<0.01,{ }^{*}{ }^{*} P<0.001$

$\mathrm{KA}=$ keratoacanthoma; $\mathrm{SCC}=$ squamous cell carcinoma; $\mathrm{MMP}=$ matrix metalloproteinase.

experienced dermatopathologist (LJ). The histological criteria used for keratoacanthoma were a cupshaped architecture with central keratin plug, basaloid layer in proliferating endophytic lobules, large cells with paler eosinophilic cytoplasm, lack of anaplasia, and a sharp outline between tumor nests and the stroma. ${ }^{21}$ As assessed by hematoxylin-eosin staining, the keratoacanthoma samples were characterized by their histologic structure, ${ }^{22}$ variable numbers of atypical cells, neovascularization, and inflammation (Table 1). The number of atypical cells was graded as 0 (less than $25 \%$ cells with atypia of the total number epidermal cells in the tumor), 1 (25-50\% of the total number of epidermal cells in the tumor showing atypia), or $2(50-100 \%)$. Neovascularization at the pushing border was graded as 0 (density of capillaries the same as in normal dermis), 1 (0-25\% more capillaries than in normal dermis), $2(25-50 \%$ ), and 3 (over $50 \%$ ). Grading for inflammation was based on the number of lymphocytes, neutrophils, and macrophages as assessed by an experienced dermatopathologist and scored as 0-2 (scarce), 3-4 (moderate), or 5-6 (abundant). The use of archival specimens was approved by the corresponding ethical committee of the Helsinki University Central Hospital, Finland.

\section{Immunohistochemistry}

Immunostaining of the sections was performed by the avidin-biotin-peroxidase complex technique (Vectastain ABC Kit; Vector Laboratories, Inc, Burlingame, CA, USA). Diaminobenzidine or aminoethylcarbatzole were used as chromogenic substrates and Mayer hematoxylin was used as a counterstain. Endogenous peroxidase was blocked by incubation with $3 \% \mathrm{H}_{2} \mathrm{O}_{2}$ for $10 \mathrm{~min}$ at room temperature. If necessary, sections were pretreated with $10 \mathrm{mg} / \mathrm{ml}$ trypsin, incubated in a $+95^{\circ} \mathrm{C}$ water bath or microwaved in citrate buffer. We used mouse monoclonal antibodies to study the localization of MMP-2 (1:100; IM33L, Oncogene Research Products, San Diego, CA, USA), MMP-7 (1:70; IM40L, Oncogene), MMP-8 (1:10; IM38L; Oncogene), MMP9 (1:50; GE-213, Research Diagnostics, Flanders, NJ, USA), MMP-10 (1:200; 5E4, Novocastra Laboratories, Newcastle, UK), MMP-13 (1:40; IM64L, Oncogene), and p16 $6^{\text {INK4 }}$ (1:350; G175-405; BD Biosciences, San Jose, CA, USA). ${ }^{17}$ Rabbit polyclonal antiserum against human MMP-19 (PC374;
Oncogene) ${ }^{14}$ was diluted 1:40 and laminin-5 $\gamma 2$ (gift from Professor Karl Tryggvason, Karolinska Institutet, Sweden) 1:1000 in 1\% BSA. ${ }^{18}$ Controls were performed with mouse immunoglobulins or with rabbit preimmune serum. Semiquantitative immunoreactivity grading for MMPs was based on positive cytoplasmic staining at the pushing border and scored as negative ( $0-5$ positive cells), $+(5-50$ positive cells), $++(50-100$ positive cells), and +++ (over 100 positive cells). Stainings for p16 and laminin-5 were graded as follows: 0 (no staining), 1 (focal, weak staining), 2 (diffuse, moderate staining), and 3 (diffuse, strong staining). The slides were analyzed independently by two investigators (TK and US-K).

\section{In Situ Hybridization}

The production and the specificity of the antisense and sense human MMP-7, -10, and -13 probes have been described previously. ${ }^{23-25}$ In situ hybridization was performed on $5-\mu \mathrm{m}$ sections as described in detail $^{26}$ to confirm immunohistochemical findings. Sections were hybridized with ${ }^{35}$ S-labeled probes $\left(3 \times 10^{4}\right.$ c.p.m. $/ \mu \mathrm{l}$ of hybridization buffer $)$ at $50^{\circ} \mathrm{C}$ for at least $18 \mathrm{~h}$ in a humidified chamber. After 20-50 days of autoradiography, the photographic emulsion was developed, and the slides were stained with hematoxylin and eosin. Samples previously positive (SCCs) for the studied mRNAs were used as positive controls. ${ }^{17}$ No signal was detected with the sense probe.

\section{Statistical Analysis}

Unpaired two-tailed $t$-test was performed to compare the number of positive cells in p16 and laminin-5 samples in MMP-13-positive and MMP13-negative groups. $\chi^{2}$ test was employed to compare the number of MMP-positive samples in keratoacanthomas vs SCCs (Table 2). $P$-value under 0.05 was considered as significant.

\section{Results}

\section{Matrilysin-1}

MMP-7 protein was detected in epithelial cells of 4/31 keratoacanthomas and 9/15 SCCs (Figure 1a and b) (Tables 1 and 2). Neovascularization was 

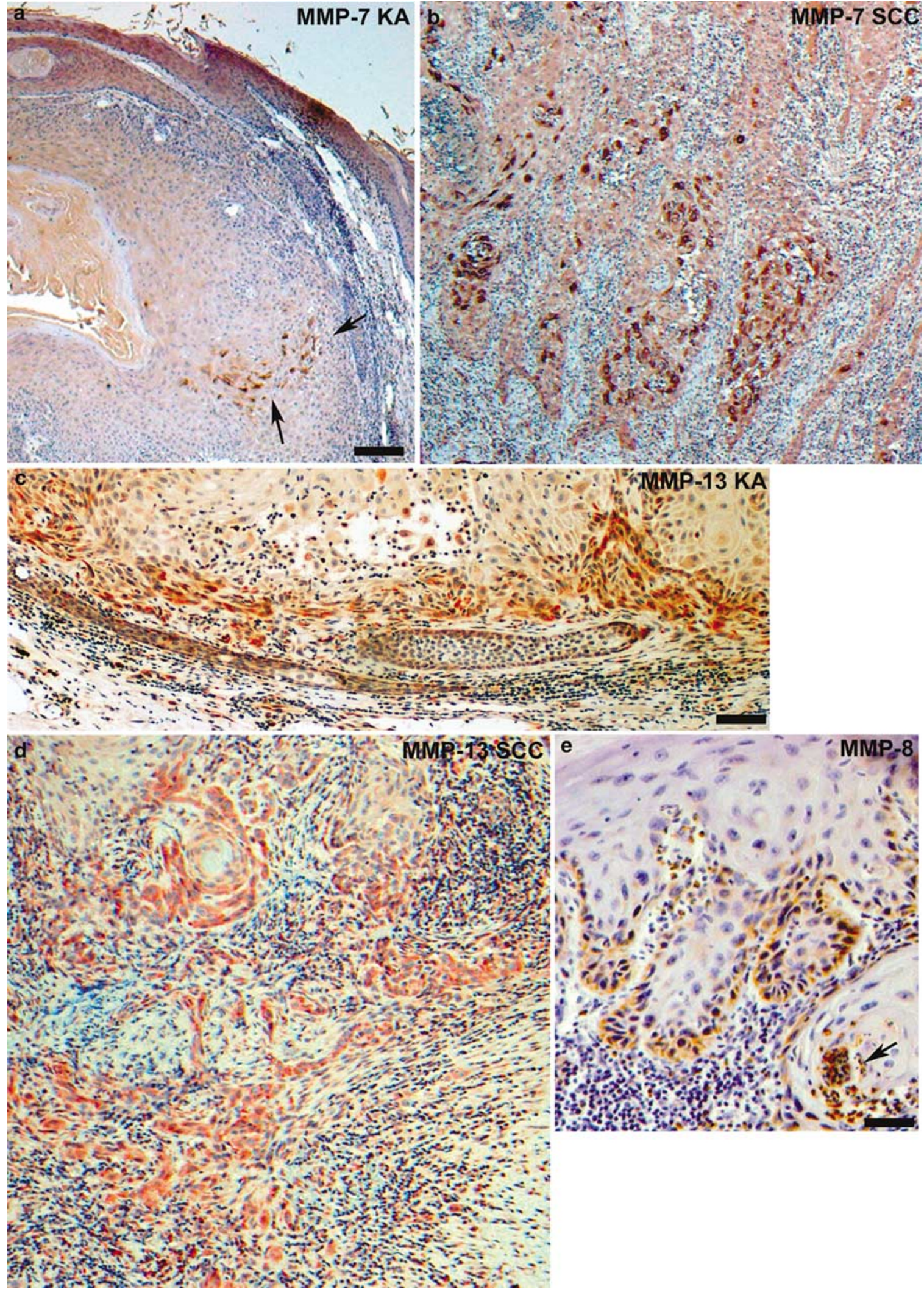

Figure 1 Immunohistochemistry for MMP-7, MMP-13, and MMP-8 in keratoacanthoma and SCC. (a) Expression of MMP-7 (arrows) by keratinocytes in keratoacanthoma. (b) MMP-7-positive keratinocytes in SCC. (c) MMP-13 expression at the pushing border in keratoacanthoma. (d) Epithelial expression of MMP-13 in SCC. (e) Expression of MMP-8 in keratinocytes in keratoacanthoma. Positive neutrophils (arrow) were detected in half of the keratoacanthoma samples. Scale bars: $125 \mu \mathrm{m}(\mathbf{a}, \mathbf{b}), 50 \mu \mathrm{m}(\mathbf{c}, \mathbf{d}), 25 \mu \mathrm{m}(\mathbf{e})$. 
observed in all MMP-7-positive keratoacanthoma samples, but the presence of MMP-7 did not associate with keratinocyte atypia or inflammation (Table 1).

\section{Collagenases}

MMP-13 was expressed by basal keratinocytes in 16/31 keratoacanthomas and 11/15 SCCs (Figure 1c and d). No correlation of MMP-13 expression with atypical cells in keratoacanthomas was noted (Table 1), but there was a trend for more abundant angiogenesis in MMP-13-positive samples $(1.25 \pm 0.77$ vs $0.80 \pm 0.96)$ (Table 1). Epithelial expression for MMP-8 was detected in 3/30 keratoacanthomas (Figure 1e), but only MMP-8-positive neutrophils were seen in 5/15 SCCs (Tables 1 and 2). MMP-8-positive neutrophils were detected in 14/32 keratoacanthomas usually localized in the upper parts of the tumors rather than near the pushing epithelial border (Table 1). All MMP-8-positive keratoacanthomas had neovascularization (Table 1).

\section{Gelatinases}

In 5/31 keratoacanthomas and 8/15 SCCs, MMP-9 expression was seen in a small number of epithelial cells at the pushing border (Figure 2a and b). In 22/ 31 keratoacanthomas, MMP-9 was produced only by macrophages and neutrophils (data not shown). Epithelial MMP-9 expression did not associate with keratinocyte atypia or angiogenesis in keratoacanthomas (Table 1). MMP-2 protein was not detected in the epithelium of any keratoacanthoma or SCC, but was abundantly expressed by fibroblasts in all the samples (Figure 2c).

\section{MMP-19 and MMP-10}

MMP-19 was generally present in epithelial keratinocytes at the pushing border of keratoacanthomas (Figure 2d) (Table 1), but only in 6/15 SCCs (Table 2). In SCCs, MMP-19 was expressed by normal hyperproliferative epidermis, but generally disappeared from the invasive cancer cell nests (Figure 2e and f). MMP-10 was expressed in the basal epithelial cells of the pushing border in 28/31 keratoacanthomas and in the basal epithelium of cancer cell nests in all SCCs (Figure 3a and b; Tables 1 and 2).

\section{Tumor Suppressor p16}

The expression of p16 tumor suppressor protein was recently shown to be induced in cells of some premalignant lesions and consistently during the early stage of SCC invasion. ${ }^{27}$ In keratoacanthomas, p16 was detected in hyperproliferating areas of the tumors independent of the number of atypic keratinocytes or the degree of inflammation (Figure 3c) (Table 1). However, some specimens had clearly fewer p16-positive cells than others (Table 1). P16 expression was stronger in MMP-13-negative samples $(1.37 \pm 0.81$ vs $1.8 \pm 0.94)$. In SCCs, p16 was mostly absent from the invasive cancer cell nests (Figure 3d) and only 7/15 samples had occasional p16-positive cells at the invasive front (Table 2).

\section{Laminin-5 $\gamma 2$}

The number of keratinocytes at the pushing border with cytoplasmic staining for laminin-5 $\gamma 2$ was variable (Table 1) (Figure 3e and f). There was a trend for stronger laminin-5 $\gamma 2$ expression in MMP13 -positive samples $(1.63 \pm 0.63$ vs $1.27 \pm 0.70)$. In most samples, laminin-5-positive keratinocytes colocalized with MMP-10-positive cells at the pushing border (Table 1), although MMP-10 was much more widely expressed (data not shown). There were no differences in the MMP, p16, and laminin-5 profiles of patients with immunosuppression compared to the others.

\section{Discussion}

During transformation into an invasive tumor, epithelial cells undergo alterations in morphology and adhesive properties, resulting in loss of normal epithelial differentiation and a switch to a more motile phenotype. Individual MMPs have unique functions during tumorigenesis and their presence in cancer tissue can be used as prognostic marker to predict tumor invasiveness. ${ }^{28}$ Therefore, we aimed to investigate the expression pattern of MMPs and their possible role as diagnostic indicators in keratoacanthomas. Very little data exist on MMPs in keratoacanthomas in contrast to SCC. MMP-1 was reported to be present in tumor cells and adjacent fibroblasts in keratoacanthoma ${ }^{29}$ and the authors concluded that it participates in the transepithelial migration of elastic fibers typical for this tumor. Furthermore, MMP-11 was detected in fibroblasts surrounding $22 \%$ of examined keratoacanthomas. ${ }^{30}$ We have recently shown that also MMP-26 is present in the pushing border of keratoacanthomas. ${ }^{11}$

As the expression of MMP-2, -7, -8, and -13 has previously been detected in malignantly transformed human keratinocytes ${ }^{10,17,31,32}$ in SCCs, but not in normal migrating keratinocytes, we chose them to begin with. Furthermore, in an epithelial carcinogenesis model of HPV16/MMP-9-/- mice, MMP-7 and MMP-13 are only seen in frank carcinoma $^{33}$ and in tumors both have been detected exclusively in malignantly transformed squamous cell carcinoma cells but not in premalignant lesions. ${ }^{34}$ MMP-7 contributes to the initiation of epithelial-to-mesenchymal transition by cleavage of E-cadherin. ${ }^{33,35}$ In keratoacanthomas, MMP-7 

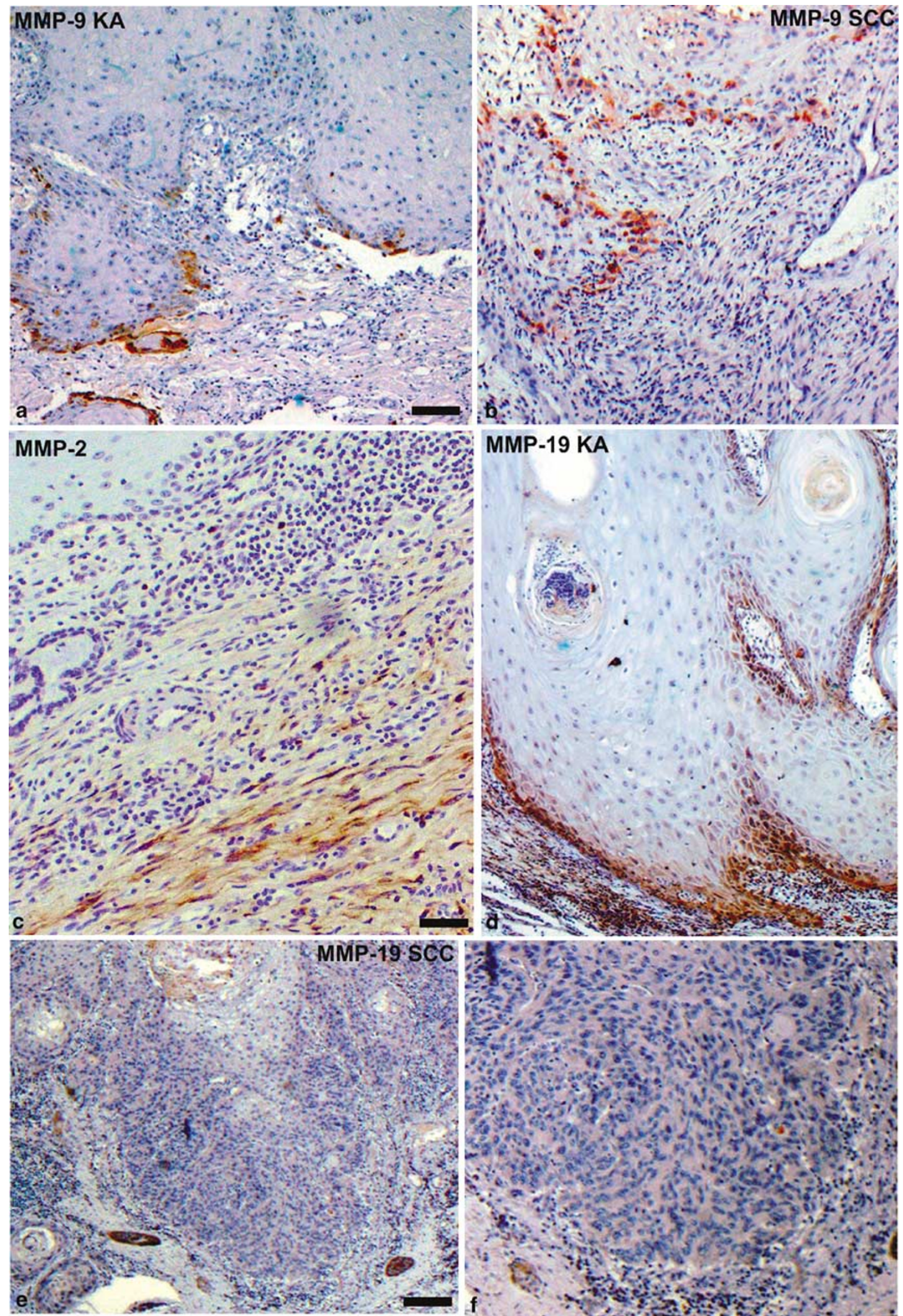

Figure 2 Expression of MMP-2, -9, and -19 in keratoacanthoma and SCC. (a) MMP-9 was detected in a small number of epithelial cells at the pushing border in keratoacanthomas. (b) Expression of MMP-9 at the invasion front of SCC. (c) MMP-2 was not detected in keratinocytes, but was abundantly expressed in fibroblasts in all keratoacanthomas. (d) MMP-19 was detected at the epithelial pushing border in almost all keratoacanthomas. (e, f) MMP-19 disappears from the invasive cancer cell nests. (f) Higher magnification of the region in (e). Scale bars: $125 \mu \mathrm{m}(\mathbf{a}, \mathbf{b}, \mathbf{e}), 50 \mu \mathrm{m}(\mathbf{c}, \mathbf{d}, \mathbf{f})$. 

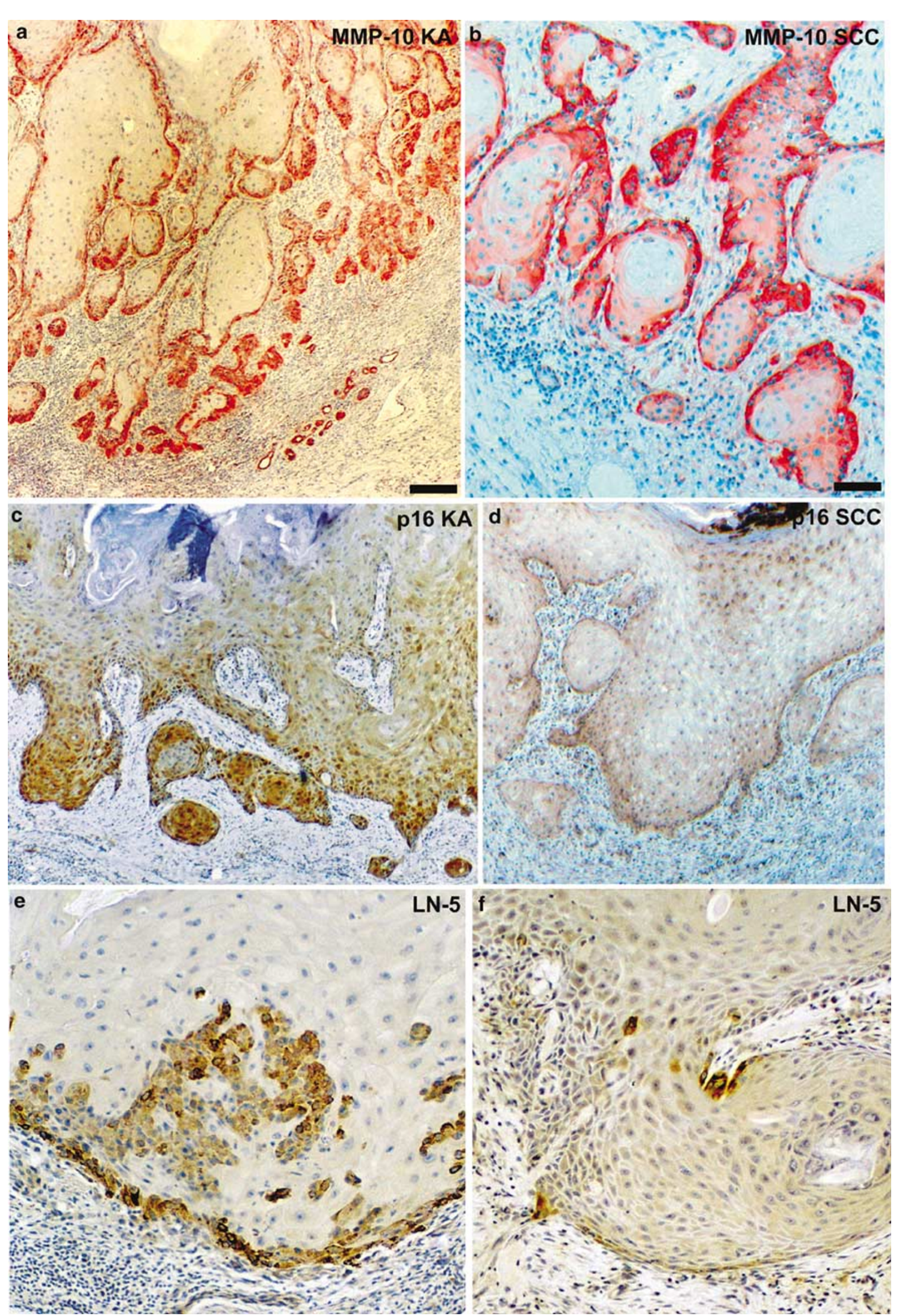

Figure 3 Expression of MMP-10, p16, and laminin-5 in keratoacanthoma. (a) Epithelial MMP-10 expression in keratoacanthoma. (b) Expression of MMP-10 in SCC. (c) Immunohistochemical staining for p16 in proliferating areas of keratoacanthoma. (d) In SCCs, p16 is mostly absent from the invasive front. The number of keratinocytes positive for laminin-5 $\gamma 2$ was higher in MMP-13-positive (e) than -negative (f) tumors. Scale bars: $125 \mu \mathrm{m}$ (a, $\mathbf{c}, \mathbf{d}), 50 \mu \mathrm{m}(\mathbf{b}, \mathbf{e}, \mathbf{f})$. 
protein was not generally expressed in keratinocytes. However, MMP-13 expression, a specific marker for malignant transformation in keratinocytes, ${ }^{36,37}$ was detected in the epithelium of half of the keratoacanthomas studied. Thus, staining for MMP-13 protein does not assist in distinguishing keratoacanthomas from grade I SCCs ${ }^{26}$ and suggests that at least a subset of keratoacanthomas cannot be classified as benign. Low expression of another collagenase, MMP-8, was found in the epithelium in three of the keratoacanthoma samples, whereas neutrophils stained positively in the majority of specimens. In contrast to sporadic epithelial expression of MMP-8 in oral SCCs, ${ }^{31}$ cancer cells were devoid of this MMP in our cutaneous SCCs.

Transformed, but also normal migrating keratinocytes, express MMP- $9,{ }^{38}$ which was detected in only 5/31 keratoacanthomas in keratinocytes (Table 2). Interestingly, Stevenson et $a 1^{39}$ have very recently shown in an EBV latent membrane protein 1 mouse model that with increasing epithelial hyperplasia and vascularization leading to keratoacanthoma, p16 and MMP-9 expression is induced. Expression of another gelatinase, MMP-2, was absent from the epithelial compartment of keratoacanthomas and SCCs. There exist contradictory reports on MMP-2 expression in cutaneous SCCs: using different antibodies than ours, Fundyler et $a l^{32}$ reported positive MMP-2 staining in keratinocytes of a subset of SCCs, but supporting our data, Tsukifugi et $a l^{40}$ found positive MMP-2 staining only in fibroblasts surrounding SCCs.

MMP-10 protein was found in the epithelium of 28/31 keratoacanthomas and all SCCs. Based on our previous results in chronic wounds and SCC, ${ }^{41}$ expression of MMP-10 does not serve as a marker of invasion, but rather reflects inflammation and matrix remodeling associated with tumor growth. Appropriately regulated and localized expression of MMP-10 in keratinocytes is required for organized migration to the wound site and in that setting laminin-5 is the most important in vivo substrate of MMP-10. ${ }^{42}$

MMP-19 was widely expressed by keratinocytes at the basal epidermal layer of keratoacanthomas and sporadically in $40 \%$ of the SCCs. We and others have previously reported that MMP-19 is absent from invasive cancer cell nests of well-differentiated SCC, ${ }^{14,34}$ and our new findings support these results. Thus, the loss of MMP-19 from basal epithelial cells of keratoacanthomas might serve as a warning sign of cancer development. In psoriasis, MMP-19 expression is associated with keratinocyte hyperproliferation ${ }^{43}$ and for this reason it might also be upregulated in keratoacanthomas.

This is the first study on laminin-5 in keratoacanthoma. Cytoplasmic laminin-5 $\gamma 2$ chain serves as a marker of normal migrating wound keratinocytes and is a good indicator of migrating cancer cells in various tumor types as well. ${ }^{18,34}$ Several MMPs are known to process laminin-5 $\gamma 2$ in vitro. ${ }^{44}$
We have previously shown that in cutaneous SCCs, laminin5 $\gamma 2$ is widely distributed along the invasive tumor front ${ }^{26,41}$ and thus our current data show that, in general, staining for laminin-5 cannot help in differentiation between keratoacanthoma and SCC. In this work, we found colocalization of laminin-5 and MMP-10, a phenomenon previously reported in squamous and basal cell cancers. ${ }^{41}$

In our keratoacanthoma samples, p16 was expressed by keratinocytes in the pushing border, although the staining intensity was variable among tumors (Table 1) perhaps owing to differences in UV exposure. ${ }^{45}$ P16 expression is activated in cells in response to basement membrane degradation/invasion and is detected in normal migrating keratinocytes as well as in chronic wounds. ${ }^{11,27}$ Less than half of our SCC samples had occasional p16-positive keratinocytes at the tumor front. Others and we have shown previously that p16 is absent from invasive areas of $\mathrm{SCCs}^{17}$ and our new results support these findings.

This is the first comprehensive study on MMP expression in keratoacanthoma. Our novel results suggest that several MMPs are abundantly expressed in this tumor (Table 2). However, the presence of MMP-7 and -9 and the loss of MMP-19 and p16 should provoke suspicion of SCC. Our finding of the keratinocyte transformation-specific MMP-13 in lesions classified as keratoacanthomas support the idea that a subset of them are incomplete SCCs.

\section{Acknowledgements}

We thank Alli Tallqvist for skillful technical assistance. This study was supported by grants from the Academy of Finland, Sigrid Jusélius Foundation, Helsinki University Central Hospital Research Funds (EVO), Finska Läkaresällskapet, Cancer Foundation of Finland, National Graduate School of Clinical Investigation, and Cancerfonden, Sweden.

\section{References}

1 Schwartz RA. Keratoacanthoma (Review). J Am Acad Dermatol 1994;30:1-19.

2 Griffiths RW. Keratoacanthoma observed. Br J Plast Surg 2004;57:485-501.

3 Goldberg LH, Silapunt S, Beyrau K, et al. Keratoacanthoma as a postoperative complication of skin cancer excision. J Am Acad Dermatol 2004;50: $753-758$.

4 Hodak E, Jones RE, Ackerman AB. Solitary keratoacanthoma is a squamous-cell carcinoma: three examples with metastases. Am J Dermatopathol 1993;15: 332-342.

5 Strieth S, Hartschuh W, Pilz L, et al. Carcinoma-like vascular density in atypic keratoacanthoma suggests malignant progression. Br J Cancer 2002;87:13011307. 
6 Kerschmann RL, McCalmont TH, LeBoit PE. P53 oncoprotein expression and proliferation index in keratoacanthoma and squamous cell carcinoma. Arch Dermatol 1994;2:181-186.

7 Boukamp P. Non-melanoma skin cancer: what drives tumor development and progression? Carcinogenesis 2005;10:1657-1667.

8 Egeblad M, Werb Z. New functions for the matrix matalloproteinases in cancer progression. Nat Rev Cancer 2002;2:161-174.

9 Hojilla CV, Mohammed FF, Khokha R. Matrix metalloproteinases and their tissue inhibitors direct cell fate during cancer development. Minireview. Br J Cancer 2003;89:1817-1821.

10 Kerkelä E, Saarialho-Kere U. Matrix metalloproteinases in tumor progression: focus on basal and squamous cell skin cancer. Exp Dermatol 2003;12: 109-125.

11 Ahokas K, Skoog T, Suomela S, et al. Matrilysin-2 (matrix metalloproteinase-26) is upregulated in keratinocytes during wound repair and early skin carcinogenesis. J Invest Dermatol 2005;124:849-856.

12 Karelina T, Goldberg G, Eisen A. Matrilysin (PUMP) correlates with dermal invasion during appendageal development and cutaneous neoplasia. J Invest Dermatol 1994;103:482-487.

13 Saarialho-Kere U, Kerkelä E, Jahkola T, et al. Epilysin (MMP-28) expression is associated with cell proliferation during epithelial repair. J Invest Dermatol 2002; 119:14-21.

14 Impola U, Toriseva M, Suomela S, et al. Matrix metalloproteinase-19 is expressed by proliferating epithelium but disappears with neoplastic dedifferentiation. Int J Cancer 2003;103:709-716.

15 Cornelius LA, Nehring LC, Harding E, et al. Matrix metalloproteinases generate angiostatin: effects on neovascularization. J Immunol 1998;161:6845-6852.

16 Nyberg P, Heikkilä P, Sorsa T, et al. Endostatin inhibits human tongue carcinoma cell invasion and intravasation and blocks the activation of matrix metalloprotease-2, -9, and -13. J Biol Chem 2003;278: 22404-22411.

17 Impola U, Jeskanen L, Ravanti L, et al. Expression of matrix metalloproteinase MMP-7 and MMP-13 and loss of MMP-19 and p16 are associated with malignant progression in chronic wounds. Br J Dermatol 2005; 152:720-726.

18 Pyke C, Romer J, Kallunki P, et al. The gamma 2 chain of kalinin/laminin is preferentially expressed in invading malignant cells in human cancers. Am J Pathol 1994;145:782-791.

19 Giannelli G, Falk-Marzillier J, Schiraldi O, et al. Induction of cell migration by matrix metalloproteinase-2 cleavage of laminin-5. Science 1997;11:225-228.

20 Mortier L, Marchetti P, Delaporte E, et al. Progression of actinic keratosis to squamous cell carcinoma of the skin correlates with deletion of the 9 p21 region encoding the $\mathrm{p} 16^{\mathrm{INK} 4 \mathrm{a}}$ tumor suppressor. Cancer Lett 2002;175:205-214.

21 Weedon D. Tumors of the epidermis. In: Houston MJ, (ed.). Skin Pathology, 2nd edn. Churchill Livingstone: London, 2002, pp 753-802.

22 Mukunyadzi P, Sanderson RD, Fan CY, et al. The level of syndecan-1 expression is a distinguishing feature in behavior between keratoacanthoma and invasive cutaneous squamous cell carcinoma. Mod Pathol 2002;15:45-49.
23 Prosser IW, Stenmark KR, Suthar M, et al. Regional heterogeneity of elastin and collagen gene expression in intralobararteries in response to hypoxic pulmonary hypertension as demonstrated by in situ hybridization. Am J Pathol 1989;135:1073-1088.

24 Kerkelä E, Ala-Aho R, Jeskanen L, et al. Expression of human macrophage metalloelastase (MMP-12) by tumor cells in skin cancer. J Invest Dermatol 2000; 114:1113-1119.

25 Vaalamo M, Mattila L, Johansson N, et al. Distinct populations of stromal cells express collagenase-3 (MMP-13) and collagenase-1 (MMP-1) in chronic ulcers but not in normally healing wounds. J Invest Dermatol 1997;109:96-101.

26 Airola K, Johansson N, Kariniemi AL, et al. Human collagenase-3 is expressed in malignant squamous epithelium of the skin. J Invest Dermatol 1997;109: 225-231.

27 Natarajan E, Saeb M, Crum CP, et al. Co-expression of p16(INK4A) and laminin 5 gamma2 by microinvasive and superficial squamous cell carcinomas in vivo and by migrating wound and senescent keratinocytes in culture. Am J Pathol 2003;163:477-491.

28 Vihinen P, Kähäri VM. Matrix metalloproteinases in cancer: prognostic markers and therapeutic targets. Int J Cancer 2002;99:157-166.

29 Ohashi A, Ishizaki M, Kawana S, et al. Mechanism of transepithelial elimination of elastic fibers in keratoacanthoma. Pathol Int 2004;54:585-594.

30 Asch PH, Basset $\mathrm{P}$, Roos $\mathrm{M}$, et al. Expression of stromelysin 3 in keratoacanthoma and squamous cell carcinoma. Am J Dermatopathol 1999;21:146-150.

31 Moilanen M, Pirila E, Grenman R, et al. Expression and regulation of collagenase (MMP-8) in head and neck squamous cell carcinomas. J Pathol 2002;197:72-81.

32 Fundyler O, Khanna M, Smoller B. Metalloproteinase2 expression correlates with aggressiveness of cutaneous squamous cell carcinomas. Mod Pathol 2004; 17:496-502.

33 Van Kempen LC, Rhee JS, Dehne K, et al. Epithelial carcinogenesis: dynamic interplay between neoplastic cells and their microenvironment (Review). Differentiation 2002;70:610-623.

34 Sadowski T, Dietrich S, Koschinsky F, et al. Matrix metalloproteinase 19 processes the laminin 5 gamma 2 chain and induces epithelial cell migration. Cell Mol Life Sci 2005;62:870-880.

35 Noe V, Fingleton B, Jacobs K, et al. Release of an invasion promoter E-cadherin fragment by matrilysin and stromelysin-1. J Cell Sci 2001;114:111-118.

36 Johansson N, Airola K, Grenman R, et al. Expression of collagenase-3 (matrix metalloproteinase-13) in squamous cell carcinomas of the head and neck. Am J Pathol 1997;151:499-508.

37 Ala-Aho R, Grenman R, Seth $\mathrm{P}$, et al. Adenoviral delivery of p53 gene suppresses expression of collagenase-3 (MMP-13) in squamous carcinoma cells. Oncogene 2002;21:1187-1195.

38 Verdolini R, Amerio P, Goteri G, et al. Cutaneous carcinomas and preinvasive neoplastic lesions. Role of MMP-2 and MMP-9 metalloproteinases in neoplastic invasion and their relationship with proliferative activity and p53 expression. J Cutan Pathol 2001;28: 120-126.

39 Stevenson D, Charalambous C, Wilson J. Epstein-Barr virus latent membrane protein 1 (CAO) up-regulates VEGF and TGF $\alpha$ concomitant with hyperplasia, with 
subsequent up-regulation of p16 and MMP9. Cancer Res 2005;65:8826-8835.

40 Tsukifugi R, Tagawa K, Hatamochi A, et al. Expression of matrix metalloproteinase $-1,-2$ and -3 in squamous cell carcinoma and actinic keratosis. Br J Cancer 1999;80:1087-1091.

41 Kerkelä E, Ala-aho R, Lohi J, et al. Differential patterns of stromelysin-2 (MMP-10) and MT1-MMP (MMP-14) expression in epithelial skin cancers. Br J Cancer 2001;84:659-669.

42 Krampert M, Bloch W, Sasaki T, et al. Activities of matrix metalloproteinase stromelysin-2 (MMP-10) in matrix degradation and keratinocyte organization in wounded skin. Mol Biol Cell 2004;15:5242-5254.
43 Suomela S, Kariniemi AL, Impola U, et al. Matrix metalloproteinase-19 is expressed by keratinocytes in psoriasis. Acta Derm Venereol 2003;83: 108-114.

44 Pirilä E, Sharabi A, Salo T, et al. Matrix metalloproteinases process the laminin-5 $\gamma 2$-chain and regulate epithelial cell migration. Biochem Biophys Res Commun 2003;303:1012-1017.

45 Hashemi RR, Bahar M, Tang $\mathrm{N}$, et al. Prediction of experimental data for an independent variable using the experimental data collected for other independent variables in a study of skin cancer caused by exposure to UV radiation. Ann NY Acad Sci 2003;993:146-157. 